\title{
Retinal upregulation of inflammatory and proangiogenic markers in a model of neonatal diabetic rats fed on a high-fat-diet
}

\author{
Jorge E Mancini ${ }^{1}$, Gustavo Ortiz ${ }^{1}$, Juan Oscar Croxatto ${ }^{2}$ and Juan E Gallo ${ }^{1 *}$
}

\begin{abstract}
Background: The contemporary peak of diabetes seems to be related to obesity, sedentary lifestyle and diet. Diabetic retinopathy is the most leading cause of blindness in adulthood in industrialized countries. Our purpose was to evaluate the effect of a high-fat-diet (HFD) on the retina of diabetic rats.

Methods: Two groups of Wistar rats were injected with streptozotocin (STZ) two days after birth using 45 and $90 \mathrm{mg} / \mathrm{kg}$, respectively. At 8 weeks the group on lower doses started to be fed on a HFD. Animals were sacrificed at 37 weeks of diabetes. A control group was made up of non-diabetic rats. Retinal flat mounts were examined using the trypsin digestion technique. Pericytes counts were compared between diabetic and control rats. Cross retinal sections were analyzed by histological techniques and immunohistochemistry and immunofluorescent technique. Primary antibodies against inflammatory and proangiogenic mediators such as RAGE, GFAP, 5-LO, VEGF and TNF-a were used for immunohistochemistry and Western Blot (WB) analyses.
\end{abstract}

Results: In the two diabetic groups we observed GFAP-positive cells with a morphology and spatial organization similar to those seen in Müller cells. Both diabetic groups had a significantly lower number of pericytes than nondiabetic animals. Increased retinal immunoreactivity of GFAP, RAGE, TNF-a, VEGF and 5-LO was seen in diabetic animals fed on HFD compared to the other groups of animals. WB analysis revealed a higher expression of 5-LO, VEGF, TNF- $a$ and RAGE in the retina of diabetic rats on HFD than in controls and diabetics fed on a normal diet. The percentage of RAGE-stained ganglion cells and ganglion cells was found to be significantly lower in animals on a HFD than in the other animals.

Conclusions: Diabetic animals fed on a HFD showed an increased upregulation of inflammatory and proangiogenic markers. This animal model may be useful to study mechanisms of diabetic retinopathy and therapeutic targets.

\section{Background}

The incidence of diabetes is higher than ever [1]. The contemporary peak of diabetes is related to a higher frequency of obesity and sedentary life as well as a high-fat-diet (HFD) [2]. These facts apply to adults and children alike [3]. For these reasons, several strategies are being used to tackle the problem of obesity and to improve diabetes management [4].

A rise in the incidence of diabetes will cause, in turn, an increase in diabetes complications, such as nephropathy,

\footnotetext{
*Correspondence: jgallo06@gmail.com

'Nanomedicine \& Vision Group, Facultad de Ciencias Biomédicas,

Universidad Austral, Pilar, Buenos Aires, Argentina

Full list of author information is available at the end of the article
}

cardiopathy and diabetic retinopathy, the latter being considered the main cause of new onset blindness in the United States [5].

Advances in molecular biology and medical technology enabled researchers to better understand the early mechanisms of diabetic retinopathy. An increased expression of glial-fibrillary-acidic-protein (GFAP) in the retina and specific abnormalities in the electroretinogram were identified a few weeks after inducing diabetes in animals [6]. These early changes were followed by retinal vascular permeability, microaneurysm development and intraretinal microvascular abnormalities (IRMA) [7].

Type 2 diabetes accounts for $90 \%$ of diabetes prevalence [5]. However, most experimental studies on diabetic 
retinopathy have been done in animal models of type 1 diabetes. In this group of animals an injection of streptozotocin (STZ) is generally used to chemically destroy pancreatic beta cells. Nevertheless, STZ can also be used to develop type 2 diabetes models in which beta cell loss takes place at a slower rate [6-8]. In our study we used the neonatal diabetic rat model fed on a HFD. Animals in this model are treated by an intraperitoneal injection of STZ at day 2 of life and fed on a HFD from week 8 onwards. For comparison purposes we also included a group of animals treated with STZ but fed on a normal diet [9]. Both animal models have been previously characterized $[9,10]$. To the best of our knowledge, no previous experimental study has investigated the role of HFD in inducing diabetic retinopathy in rats, animals often used in preclinical research. This type of diet is known to accelerate metabolic disorders and their microvascular complications. Bearing in mind the increasing role of obesity and fat food intake in the pathophysiology of diabetes [3,11], we aimed at determining the effect of a HFD on the retina of diabetic rats. Results reported herein were compared to results from non-diabetic and diabetic rats fed on a normal diet.

\section{Methods}

\section{Rat models of diabetes}

Diabetic rats on a HFD. Pregnant Wistar rats provided by Comisión Nacional de Energía Atómica (CONEA, Buenos Aires) were housed in the animal facilities at $21+/-1^{\circ} \mathrm{C}$ on a 12-h light-dark cycle. They were daily examined until delivery. Two days after birth, newborn rats were intraperitoneally injected with STZ (45 mg/kg) (SigmaAldrich, St- Louis, MO), in $0.1 \mathrm{ml}$ of $0.1 \mathrm{M}$ solution of citrate buffer of $154 \mathrm{mM}$ of $\mathrm{NaCl}$ at $\mathrm{pH} 4.5$ [9,12,13]. The animals remained with their mothers until 21 days of age. Eight weeks after birth, STZ-treated animals were fed with a home-made HFD (25.62\% of fat content), (Tables 1 and 2), which was prepared every week and stored at $-7^{\circ} \mathrm{C}$. Blood samples of $32 \mu$ l obtained by tail snipping were utilized to measure blood glucose levels using the Reflotron System (Boehringer Mannheim, Germany) one week after initiating the diet and every month thereafter. Rats which showed glycemic levels $>160 \mathrm{mg} / \mathrm{dl}$ after one week on the HFD were included in the study.

Diabetic rats fed on a normal diet. Two days after birth animals were intraperitoneally injected with $90 \mathrm{mg} / \mathrm{kg}$ SZT (Sigma-Aldrich, St-Louis, MO) in $0.1 \mathrm{M}$ of citrate buffer in $154 \mathrm{mM}$ of $\mathrm{NaCl}$ at $\mathrm{pH}$ 4.5. Two days after induction blood was drawn intracardially following the method described by Bonner-Weir [9]. Blood glucose was determined in puppies. For the quantification of glycemia, $32 \mu \mathrm{l}$ of blood and reagent strips (Reflotron System, Boehringer Mannheim, Germany) were used. Animals were labeled as diabetic if they showed hyperglycemia $\geq 200 \mathrm{mg} / \mathrm{dl}$. Animals remained with their mothers until 21 days of age.
Table 1 Composition of high-fat-diet (HFD) and standard diet

\begin{tabular}{|c|c|c|c|c|c|}
\hline & & Standa & & HFD & \\
\hline & & Total & Subtotal & Total & Subtotal \\
\hline Carbohydrates & & $54.22 \%$ & & $28.86 \%$ & \\
\hline Protein & & $23.62 \%$ & & $23.60 \%$ & \\
\hline Aminoacids & & $2.25 \%$ & & $2.25 \%$ & \\
\hline & Lysine & & $51.11 \%$ & & $51.11 \%$ \\
\hline & Methionine & & $26.66 \%$ & & $26.66 \%$ \\
\hline & Threonine & & $22.22 \%$ & & $22.22 \%$ \\
\hline Fat & & $2.71 \%$ & & $25.62 \%$ & \\
\hline & Saturates & & $24.22 \%$ & & $46.46 \%$ \\
\hline & Monounsaturated & & $30.21 \%$ & & $47.51 \%$ \\
\hline & Polyunsaturated & & $45.6 \%$ & & $6.34 \%$ \\
\hline lons & Calcium & $1.40 \%$ & & $1.60 \%$ & \\
\hline & Sodium & $0.05 \%$ & & $0.05 \%$ & \\
\hline & Magnesium & $0.18 \%$ & & $0.18 \%$ & \\
\hline
\end{tabular}

Control rats. Non-diabetic control animals with no STZ injection were fed on standard chow $(2.71 \%$ of fat content). See Tables 1 and 2 .

Ten diabetic rats were sacrificed after 37 weeks of diabetes (45 weeks old in the HFD-SZT group and 37 weeks old in the SZT group with no diet) while ten non-diabetic rats were killed at 41 weeks of age. Animals were handled according to the ARVO Statement for the Use of Animals in Ophthalmic Research.

\section{Clinical parameters}

Each animal was weighed using a standard scale at 8 weeks of life and before death. Lipidemia levels were measured using the Reflotron System every month and before the animal was killed.

\section{Fatty acid profile}

The chemical compound of a HFD and a conventional diet are shown in Table 2. In brief, the HFD contains $25.6 \%$ of fat $(46.4 \%$ of saturated, $47.5 \%$ monounsaturated and $6.3 \%$ of polyunsaturated fats) while the conventional diet contains $2.71 \%$ of fat $(24.2 \%$ of saturated, $30.2 \%$ of monounsaturated and $45.6 \%$ of polyunsaturated fats). The diet's chemical compound was analyzed using animal and vegetable fats and oil-analysis by gas chromatography of fatty acids methyl esters, according to The International Organization for Standardization (ISO 5508: 1990-E) (Table 2).

\section{Histological examination}

Rats were anesthetized by an intraperitoneal injection of $350 \mathrm{mg} / \mathrm{kg}$ of chloral hydrate. The eyes were removed and fixed in 4\% paraformaldehyde (Sigma-Aldrich, St Louis, 
Table 2 The constitution of fatty acids

\begin{tabular}{lll}
\hline Fatty acids & High fat diet & Standard diet \\
\hline C4:0 & 0.01 & 0.04 \\
C6:0 & - & 0.05 \\
C10:0 & 0.02 & - \\
C12:0 & 0.07 & - \\
C13:0 & 0.02 & -- \\
C14:0 & 3.15 & 0.53 \\
C14:1 TRANS & 0.19 & 0.13 \\
C14:0 CIS & 0.2 & 0.12 \\
C15:0 & 0.84 & 0.15 \\
C15:1 & 0.49 & 0.18 \\
C16:0 & 24.96 & 15.62 \\
C16:1 TRANS & 0.46 & - \\
C16:1 CIS & 3.36 & 1.12 \\
C17:0 & 2.17 & 0.45 \\
C17:1 TRANS & 0.11 & -- \\
C17:1 CIS & 0.83 & 0.17 \\
C18:0 & 14.9 & 6.74 \\
C18:1 TRANS & 2.84 & 0.4 \\
C18:1 CIS & 38.63 & 27.73 \\
C18:2 TRANS & 0.8 & 0.08 \\
C18:2 CIS & 5 & 42.12 \\
C20:0 & 0.1 & 0.34 \\
C18:3 CIS & 0.54 & 0.28 \\
C20:1 & 0.6 & 100 \\
C22:0 & 0.02 & \\
C22:1 CIS & --18 \\
TOTAL & & -100 \\
\hline
\end{tabular}

MO). Animals were sacrificed by an overdose of chloral hydrate. The anterior segment of the eye and the vitreous were removed and the eye-cup was left one day for fixation. They were then immersed for cryoprotection in 4 concentrations of glucose $(5 \%, 7.5 \%, 10 \%$ and $20 \%$, overnight) and interlocked with resin. Ten-micron cryosections were obtained (Shandon AS325 Retraction) and stained with haematoxylin and eosin (H\&E) as well as periodic acid-Schiff (PAS) for microscopic examination using an Eclipse Nikon E800 Microscope (Tokyo, Japan).

\section{Immunohistochemical and immunofluorescent analyses}

The eye was removed and fixed for 48 hours in $4 \%$ paraformaldehyde (Sigma-Aldrich, St Louis, MO). The eye-cups were then dissected and fixed in $4 \%$ paraformaldehyde in a phosphate buffer for one hour. They were then immersed for cryoprotection in 4 concentrations of glucose $(5 \%$,
$7.5 \%, 10 \%$ and $20 \%$ overnight) and interlocked with resin. Ten-micron sections were obtained and fixed on polylisine-treated glass slides (Shandon AS325 Retraction).

The GFAP expression was analyzed using the primary monoclonal anti-mouse anti- GFAP antibody (BIOGENEX, 4600 Norris Canyon Road, San Ramon, CA, USA). For immunohistochemistry, the sections were first incubated in biotinylated goat-anti-mouse IgG, then in avidin-biotin peroxidase complex Kit and finally in 3.3'-diaminobenzidine (DAB)/nickel solution. For immunofluorescence, axial sections were revealed using the secondary goat-anti mouse antibody with fluorescein. Immunofluorescent analysis was done using the Eclipse Nikon Microscope (Tokyo, Japan).

The following primary antibodies were used for immunohistochemical analyses:

The anti-mouse polyclonal antibody against vascular endothelial growth factor (VEGF) (1:500) (Santa Cruz Biotechnology Inc. 2145 Delaware Avenue Santa Cruz, CA, USA); the anti-mouse polyclonal antibody against receptor advanced-glycation end products (RAGE) (1:300) (AnaSpec Inc, San Jose, CA, USA); the anti-mouse polyclonal antibody against 5-lipoxygenase (5-LO) (1:500) (Assay biotechnology company, San Francisco, CA, USA) and the anti-mouse polyclonal antibody against tumor necrosis factor-alpha (TNF- $\alpha$ ) (1:100) (Assay Biotechnology Company, San Francisco, CA, USA). The process for immunohistochemical and immunofluorescent analyses was similar to that described for GFAP.

\section{Western blot (WB)}

Isolated retinas were rinsed in the lysis buffer $(5 \mathrm{mM}$ Tris-HCl pH: 6.8, $2 \mathrm{mM} \mathrm{MgCl} 2,2 \mathrm{mM}$ EDTA, $65 \mathrm{mM}$ $\mathrm{NaCl}, 1 \%$ Triton X-100) and cocktail protease inhibitor (Sigma-Aldrich, St. Louis MO, USA). Protein concentration was determined according to Bradford method [14]. Total protein $(10 \mu \mathrm{g}$ per well) was electrophoresed on a $12 \%$ SDS-polyacrylamide gradient gel and blotted onto nitrocellulose. The blot was incubated with primary antibody, washed and further incubated in a secondary antibody. The bands were visualized using the enhanced chemiluminescence detection system (ECL, Amersham, Arlington Heights, IL, U.S.A.). The primary antibodies against 5-LO (Assay Byotech, USA), VEGF (Santa Cruz Biotechnology, CA), TNF- $\alpha$ (Assay Biotechnology Company), RAGE (AnaSpec Inc), $\beta$-actin (Santa Cruz Biotechnology, CA) and glyceraldehyde-3-phosphate dehydrogenase (GFPDH) (Santa Cruz Biotechnology, CA) used at 1:1000, 1:500, 1:500, 1:1000, 1:1000 and 1:500 dilutions, respectively, were utilized for WB.

Retinal protein was isolated in pools from four control rats (41 weeks old), diabetic rats on a HFD and diabetic rats on a normal diet (37 weeks of diabetes). At least three independent experiments were performed for each condition. 


\section{Trypsin digestion technique}

After the cornea was incised, the eyeball was fixed by immersion for a minimum of 4 hours in $4 \%$ formalin buffered with $50 \mathrm{mM} \mathrm{Na}-\mathrm{K}$ phosphate (pH 7.2). As explained before, the retina was dissected and placed again in $4 \%$ buffered formalin for 1 hour more. The retina was cut into a segment convenient for handling and washed overnight in running water. Thereafter, it was incubated at $37^{\circ} \mathrm{C}$ in a solution of $3 \%$ trypsin (Difco 1:250) and $0.1 \mathrm{M}$ tris buffer ( $\mathrm{pH} \mathrm{7.8)}$ for $1-3$ hours. The incubation was finished when the medium became cloudy and the tissue showed signs of digestion. The internal limiting membrane was peeled off in one sheet. The network of vessels was freed of adherent retinal tissue by gentle shaking, mounted on a clean slide and allowed to dry. The preparation was stained with PAS and eosin [15].

\section{Image analysis \\ Pericyte count}

Image analysis measurements were made using a KS400 system (Kontron Elektronic/Zeiss, Eching, Germany) and a Nikon DXM 1200 digital camera (Tokyo, Japan) mounted onto an Eclipse Nikon E-800 microscope for image acquisition. Briefly, images were digitalized in a rectangular frame of $1280 \times 960$ pixels using the $40 \times$ objective in the photo mode of illumination intensity. To adjust for possible defects in the illumination of the optical pathway, a low-pass image was produced for subtraction and background shading correction. After that, a gray value for image segmentation was interactively chosen. In order to define a threshold gray level, all the pixels whose gray value informative content was lower or higher than the segmentation gray were set to white and the others, to black. Pericytes and endothelial cells were counted by an observer in 10 randomly selected sectors of each retina. The number of pericytes was normalized to the relative capillary density (number of cells per millimeter squared of capillary area -3 pixels $^{2}$ of capillary area $=1 \mathrm{~mm}^{2}$ ). The mean value of pericytes and endothelial cells was calculated in each animal. Samples were evaluated in a masked fashion. We did the same to count acellular capillaries and intercapillary bridges.

Statistical analysis was carried out using one-way analysis of variance and Newman-Keuls Multiple Comparison Post-Test to compare the number of pericytes between diabetic (37 weeks of disease) and control rats (41 weeks of age). All elements out of the two standard deviations were eliminated.

\section{Measurement of retinal thickness. Ganglion cell count}

Microscopic evaluation of retinas included scanning tissue sections for evidence of gross disease followed by morphometric analysis, which involved measuring retinal thickness and the number of cells in the ganglion cell layer (GCL).
Retinal transversal sections were divided into three equal parts (inner, middle and outer) from the optic disc to periphery. Cells of the GCL were quantified by counting cells in the middle part of the retina. Ten fields (275 $\mu \mathrm{m}$ each of horizontally diameter) were counted. The mean value of these variables was calculated for each animal. Thickness measurements of the entire retina as well as from the inner plexiform layer (IPL) to the photoreceptors layer were taken in the posterior retina from 100 to $500 \mu \mathrm{m}$ from the optic disc to the periphery, in two different points of each field in each group. Samples were evaluated in a masked fashion.

Image analyses were performed using a Nikon DXM 1200 digital camera (Tokyo, Japan) mounted onto an Eclipse Nikon E-800 microscope for image acquisition. Images were digitalized in a rectangular frame of $1280 \times$ 960 pixels using the $40 \times$ and $10 \times$ objectives for GCL cell count and thickness measurements, respectively. To adjust for possible defects in the illumination of the optical pathway, a low-pass image was produced for subtraction and background shading correction.

Statistical analysis was carried out using one-way analysis of variance and Newman-Keuls Multiple comparison Post-Test to compare the number of cells in the GCL between diabetic (37 weeks of disease) and control rats (41 weeks of age). All elements out of the two standard deviations were eliminated.

\section{Percentage of ganglion cells stained with RAGE among diabetic rats}

Immunohistochemical images of ganglion cells stained with RAGE were digitalized in a rectangular frame of $1280 \times 960$ pixels using the $20 \times$ objective in the photo mode of illumination intensity. Ten images were used for each slide. Four eyes of four animals from each group were analyzed. Twenty slides were utilized in each animal. The percentage of stained ganglion cells was obtained from each slide. Mean and standard deviation were compared between diabetic animals.

\section{Results}

Diabetic rats with and without a HFD had higher glycemia levels (range 160-390 mg/dl) at 37 weeks of diabetes compared to age-matched control rats (range $80-120 \mathrm{mg} / \mathrm{dl}$ ). Similarly, increased levels of triglyceridemia were observed in diabetic animals (Table 3).

The number of pericytes was found significantly lower in both groups of diabetic rats than in control animals (Figure 1). Vessel dilations, acellular capillaries and capillary obliterations were seen in both diabetic groups (Figure 2).

Retinal thickness was reduced in the diabetic groups compared to age-matched controls (Figure 3A,B). Control animals had retinal GCLs with densely packed cells. 
Table 3 Weight, glycemia, trygliceridemia and cholesterolemia in diabetic and control rats

\begin{tabular}{lllllllll}
\hline \multirow{2}{*}{ Animal group } & WA & WD & $\begin{array}{c}\text { No of } \\
\text { rats }\end{array}$ & & \multicolumn{5}{c}{ Parameters* } \\
\cline { 3 - 8 } & & & & & Weight* $^{* *}$ & Gl*** & Tri $^{* * *}$ & Ch $^{* * * *}$ \\
\hline DBT-HFD & 8 & 0 & 12 & 320 & 111 & N-M & N-M \\
DBT-HFD & 9 & 1 & 12 & 340 & 224 & N-M & N-M \\
DBT-HFD & 20 & 12 & 12 & 434 & 253 & 139 & 116 \\
DBT-HFD & 45 & 37 & 6 & 449 & 212 & 114 & 115 \\
DBT (2 days old) & 0 & 0 & 10 & 7.26 & 321 & N-M & N-M \\
DBT & 37 & 37 & 10 & 388 & 353 & 116 & 121 \\
Control & 41 & - & 12 & 524 & 115 & 91 & 119 \\
\hline
\end{tabular}

N-M: not measured; WD: weeks on HFD; WA: weeks of age; Gl: Fast glycemia; Tri: triglyceridemia; Ch: cholesterolemia; ${ }^{*}$ Mean ; ${ }^{* *} \mathrm{gr} ;{ }^{* * *} \mathrm{mg} / \mathrm{dl}$.

Diabetic animals with fasting glycemia below $160 \mathrm{mg} / \mathrm{dl}$ were excluded.

Control animals with fasting glycemia above $130 \mathrm{mg} / \mathrm{dl}$ were not included in the study.

There was a typically uniform distribution of cells, except for an occasional blood vessel that made a little space between cells (Figure 3C,D), whereas in diabetic rats there was a dropping pattern of ganglion cells from central to peripheral retina. Besides, ganglion cells of both diabetic groups were significantly fewer than in controls $(\mathrm{p}<0.001)$ (Figure 3C).

Unspecified vitreoretinal interphase findings were quite similar in all animal groups (not shown).

GFAP was expressed in the retinal fiber layer of diabetic and non-diabetic animals. Staining was increased in diabetic rats, but the group fed on a HFD showed more widespread GFAP immunoreactivity in the retinal periphery than did the group fed on a normal diet (Figure 4). In HFD animals GFAP was expressed in cells with morphology and spatial organization similar to those seen in Müller cells (Figure 4).
RAGE expression was found to be upregulated in diabetic animals. Its expression at the inner nuclear layer (INL) was only seen in diabetic rats on a HFD (Figure 5). Percentage of ganglion cells stained with RAGE was significantly increased in diabetic rats on HFD compared to diabetic rats fed on a normal diet (Figure 6). Besides, RAGE expression on WB was found to be higher in diabetic animals fed on HFD than in the other groups of rats (Figure 5).

Upregulation of TNF- $\alpha$ was observed in diabetic animals on a HFD. Immunoreactivity was found in the IPL and outer plexiform layer (OPL) (Figure 7). The WB revealed a higher expression of TNF- $\alpha$ in diabetic rats fed on a HFD than in diabetic rats fed on a normal diet and controls (Figure 7).

VEGF was seen in the retina in the FL, OPL and RPE (Figure 8). WB analyses showed a higher expression of VEGF in rats fed on a HFD than in controls and diabetic rats on a normal diet (Figure 8).

Immunoreactivity of 5-LO was observed in the GCL, in the INL and in the retinal pigment epithelium (RPE) of both diabetic rats and controls. Although there was a similar pattern among diabetic rats, staining extension was greater in diabetic animals on a HFD than in diabetic animals on a normal diet. In addition, a higher expression of 5-LO was observed on WB in animals fed on a HFD compared to controls and diabetic rats on a normal diet (Figure 9).

\section{Discussion}

We have conducted an experimental study of diabetic retinopathy in diabetic rats fed on a HFD. In these animals inflammatory and proangiogenic molecules were found to be upregulated. To the best of our knowledge, this is the first study done in diabetic rats in which a
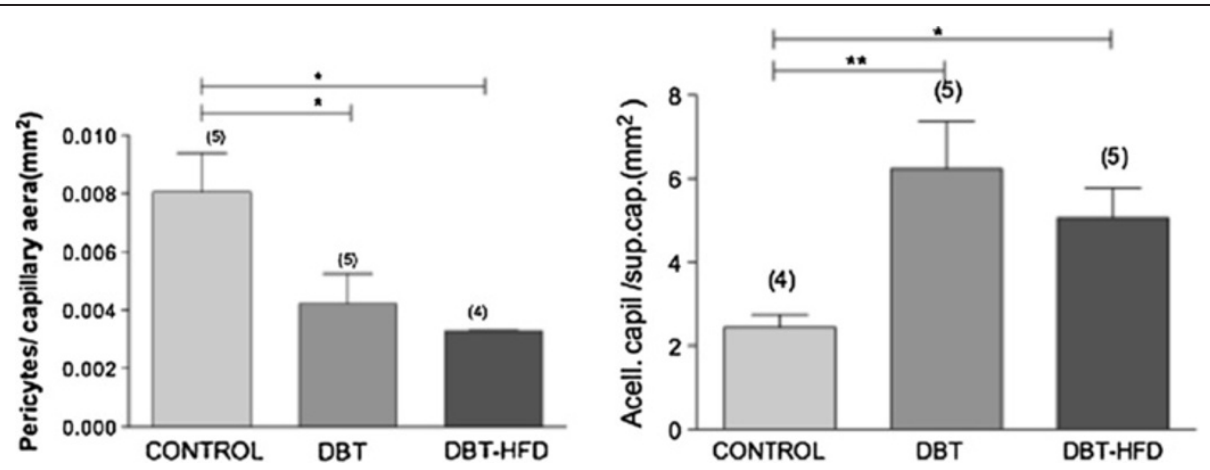

Figure 1 Pericyte count in diabetic and control rats. The number of pericytes per capillary area was found to be significantly lower in the retinas of diabetic rats compared to controls but there were no differences between the two diabetic rat groups. The number of acellular capillaries per capillary area was found to be higher in the retinas of both diabetic rat groups compared to controls, but there were no differences between the two diabetic rat groups. The total number of pericytes and acellular capillaries was manually counted in 10 randomly selected fields of each retina. The number of pericytes and acellular capillaries was normalized to the relative capillary density (number per millimeter squared of capillary area -3 pixels ${ }^{2}$ of capillary area $\left.=1 \mathrm{~mm}^{2}\right)$. Samples were evaluated in a masked fashion $\left({ }^{* * *} p<0.0001,{ }^{*} p<0.05\right)$. 


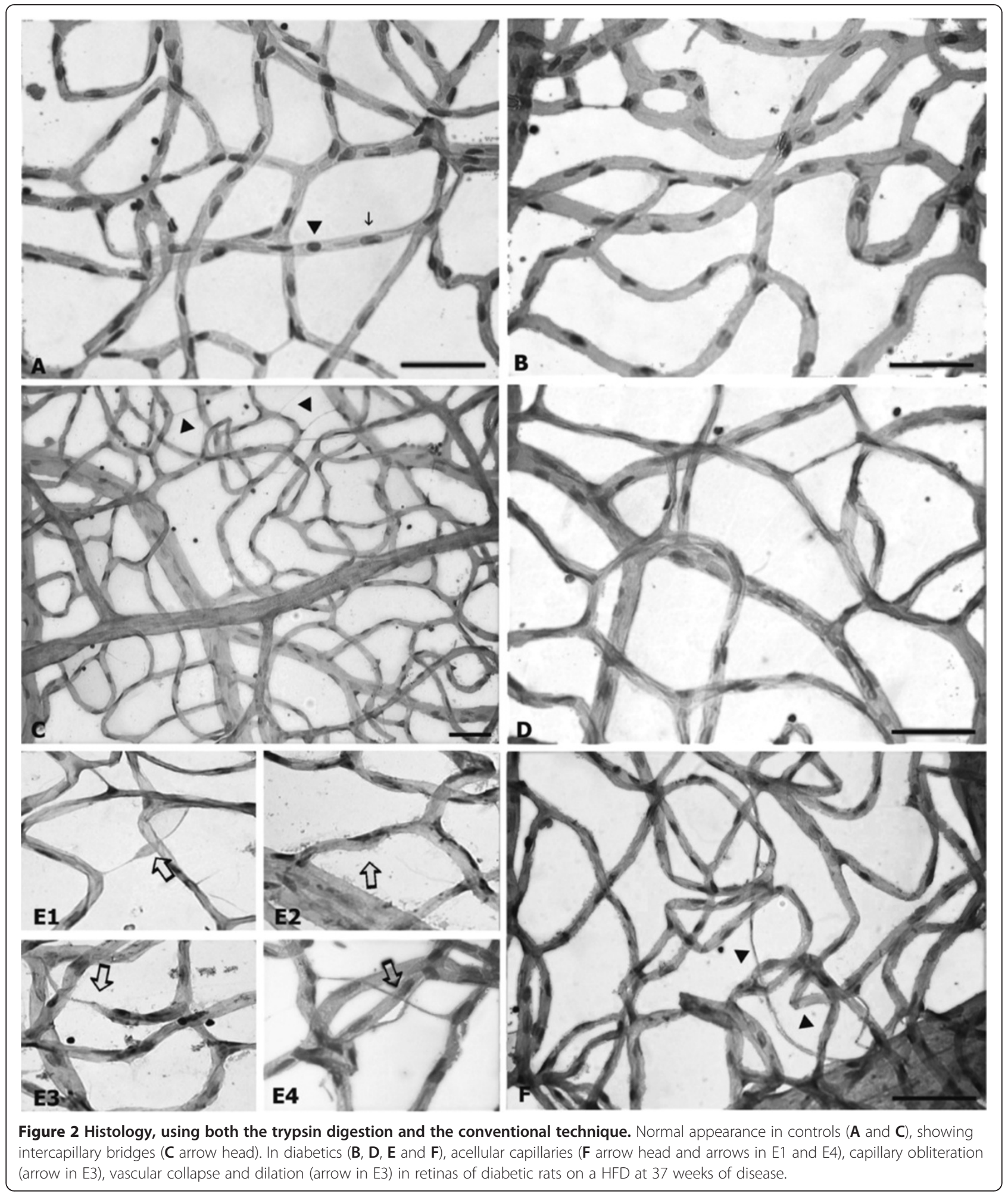

HFD along with glycemia have a synergistic effect that leads to retinopathy development.

Most diabetic retinopathy studies carried out in rodents involve type 1 diabetes models. In this model the injury induced by the STZ injection causes complete destruction of pancreatic beta cells. This is different from what occurs in type 2 diabetes models in which beta cell loss takes place at a slower rate. However, the use of both a HFD and STZ in our diabetes model might confuse the reader. This model includes neonatal rats in 


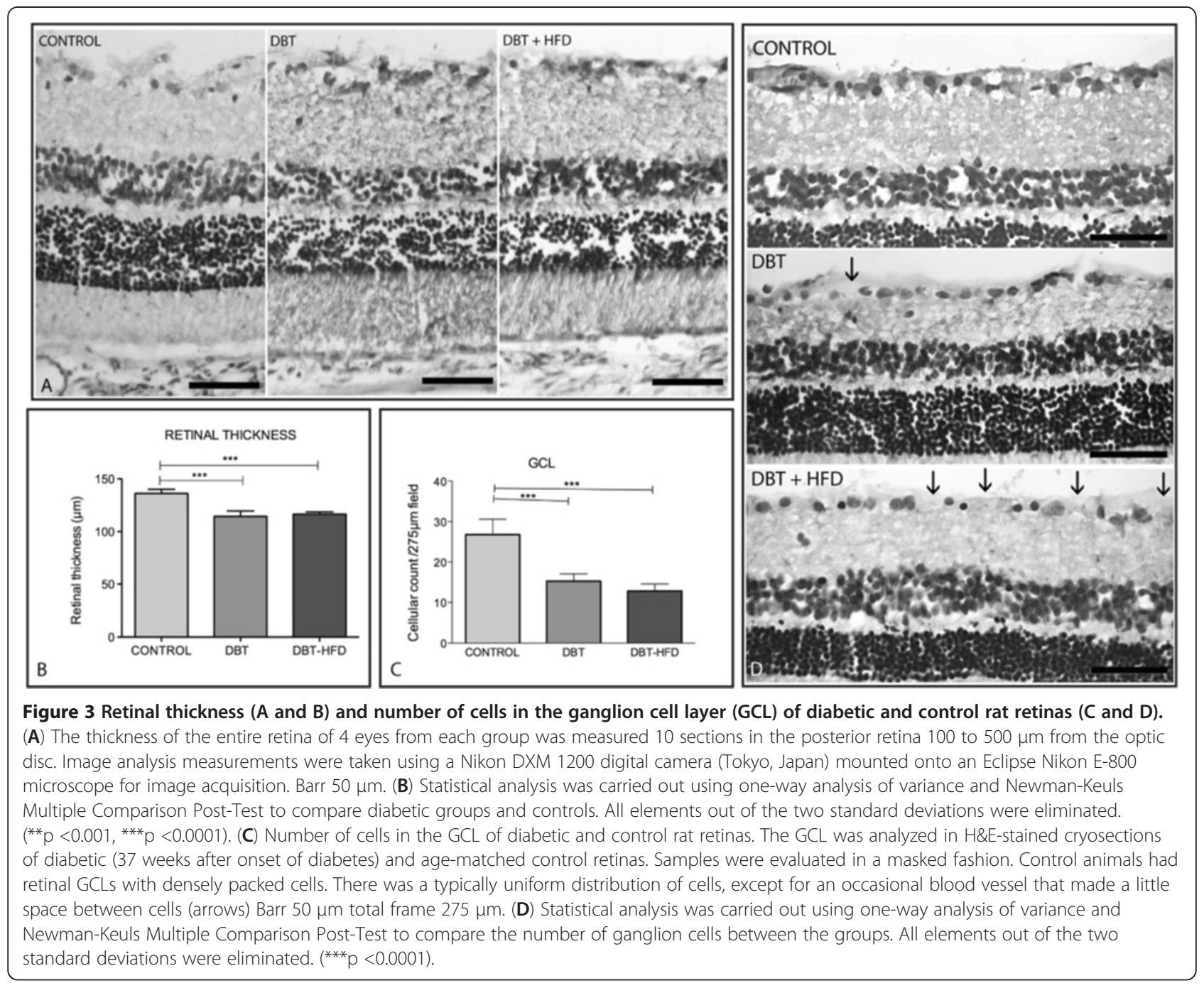

which progenitor cells are still present in the pancreas after birth, inducing the regeneration of beta-cells and keeping up insulin secretion. Our model of diabetes was previously characterized by other investigators $[12,16]$ and recommended for studies on diabetic complications associated with obesity [17].

Glycemia and triglyceridemia levels were found to be more elevated in diabetic animals than in controls. In our research we measured total cholesterol levels, but not low density and high-density lipoprotein levels. This might have yielded interesting data given the harmful effect of LDH on the cardiovascular system [18].

The fatty acid chemical compound diet in HFD animals shows a profile known to be risky for cardiovascular disease and favours cell damage [19-21]. Our results are consistent with this. In our group of animals on a HFD there was a significantly higher frequency of vessel abnormalities in the form of acellular capillaries and loss of pericytes as well as ganglion cells than in non-diabetic controls. Although several factors could have been involved in this unbalanced situation, we think that the decrease of docosahexaenoic acid-derived neuroprotectin D1 (NPD1) [22-24] was undoubtedly a major contributing factor. Arachidonic acid (AA) is catalyzed by the enzyme 5 -LO, resulting in the production of platelet activating factor, prostaglandines, leukotrienes and thromboxanes, which are all metabolites involved in inflammatory diseases [25]. The biosynthesis of leukotrienes was found to be elevated in diabetic mice [26]. Leukotrienes increase vascular permeability and play a crucial role in activating the nuclear factor kappa B (NF- $\kappa \mathrm{B})$ proinflammatory pathway [27]. The 5-LO enzyme has been involved in diabetes and its complications [28]; for example, in cardiac ischemia reperfusion where the use of 5-LO RNAi showed protective effects [29]. In the retina, the 5 -LO promotes the presence of lipid inflammatory mediators in ischemic disorders [30] and it has also caused retinal capillary degeneration in a diabetes mouse model [31]. In our study 5-LO immunoreactivity was identified in the RPE and GCL of diabetic animals. However, protein expression was 


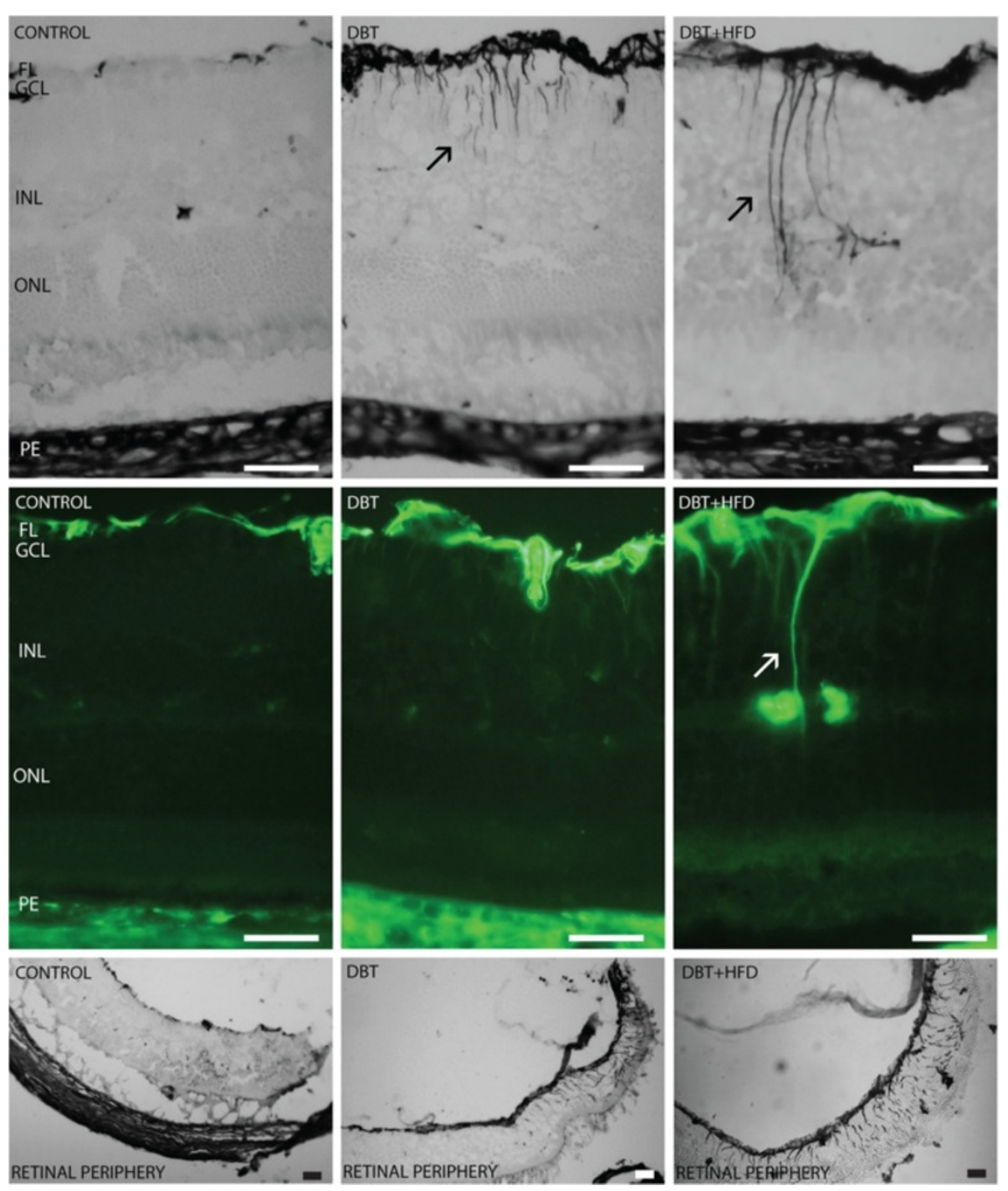

Figure 4 Immunohistochemical and immunofluorescent expression of GFAP. Immunohistochemical and immunofluorescent analyses of cross sections of diabetic retinas showed an increased expression of GFAP in cells with a morphology and spatial organization similar to those seen in Müller cells (arrow). GFAP immunoreactivity is higher in diabetic rats than in controls. The expression of GFAP in the peripheral retina was much more extended in diabetic rats fed on a HFD than in rats on a normal diet. Barr $50 \mu \mathrm{m}$.

found to be significantly higher in animals fed on a HFD. Interestingly, 5-LO has recently been discovered as a potential therapeutic target for ocular diseases associated with angiogenesis [32,33]. Moreover, zileuton, a specific 5LOX inhibitor, may play a role in the reduction [34] of angiogenesis.

RAGE is known to be involved in diabetic retinopathy pathogenesis. In early diabetes advanced-glycation end products modulate retinal vasopermeability and alter interendothelial cell tight junction integrity, leading to inner blood retinal barrier dysfunction. This seems to result from the upregulation of VEGF [35]. RAGE ligation in endothelial cells activates the NF- $\mathrm{kB}$. An increase of cells with activated NF- $\mathrm{kB}$ has been found in diabetic rats with RAGE-dependent regulation [36]. RAGE and its ligands are increased in the vitreous cavity of eyes with proliferative diabetic retinopathy, suggesting a role in the development of proliferative retinal diseases $[28,37]$. RAGE and VEGF may constitute a powerful association that hastens diabetic retinopathy.

Early in the course of diabetic retinopathy, Müller cells markedly upregulate the expression of GFAP [6], a nonspecific response to pathophysiological conditions. Müller cells produce factors capable of modulating blood flow, vascular permeability, and cell survival, and their processes surround all blood vessels in the retina. The role of these cells in the pathogenesis of retinal microangiopathy has therefore been established [38]. 


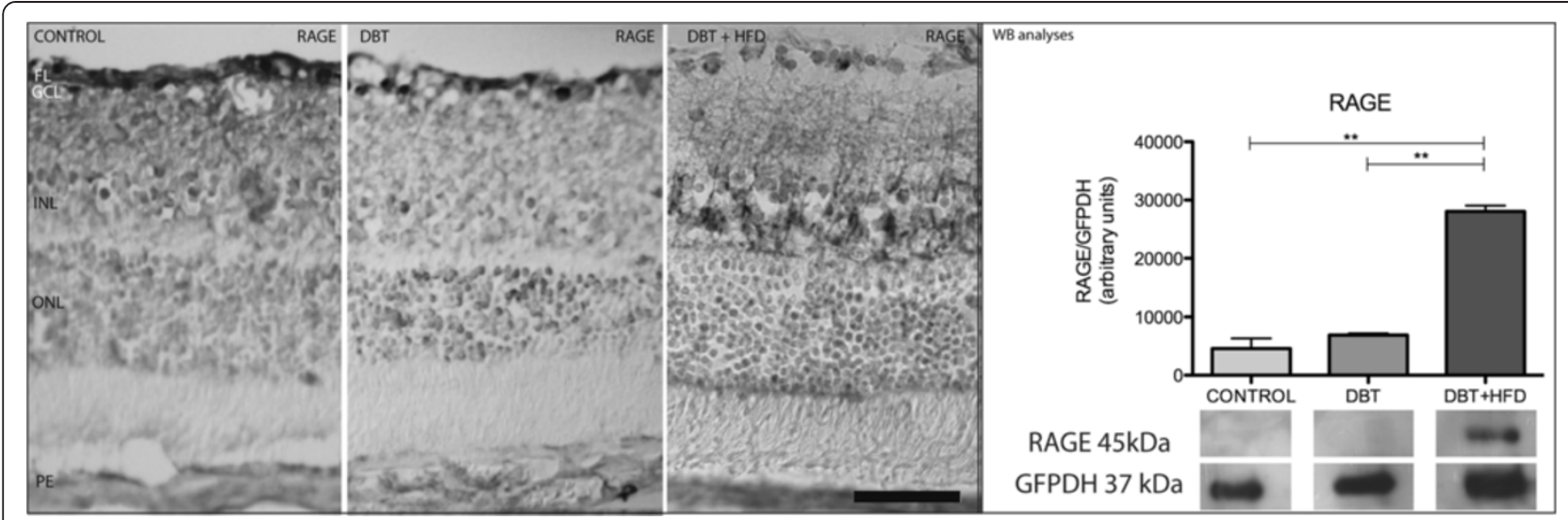

Figure $\mathbf{5}$ Immunohistochemical analysis of RAGE expression. A higher expression was found in diabetic rats than in controls. RAGE expression in the inner nuclear layer (INL) was only observed in diabetic rats on a HFD. Barr 50 mm. Western blot shows a higher expression in diabetic rats on a HFD (** $\mathrm{p}<0.05)$.

VEGF is known to be an essential agent in retinal inflammation, vascular leakage, hypoxia and angiogenesis. In our group of diabetic animals fed on HFD, VEGF immunoreactivity was observed in the fiber layer, outer plexiform layer and RPE layer. VEGF can be produced by vascular endothelial cells, glial and ganglion cells, pericytes and retinal pigment epithelium cells. Based on their morphology and retinal localization, VEGF immunoreactivity was identified in retinal pigment epithelial cells and probably also in endothelial and glial cells. In a

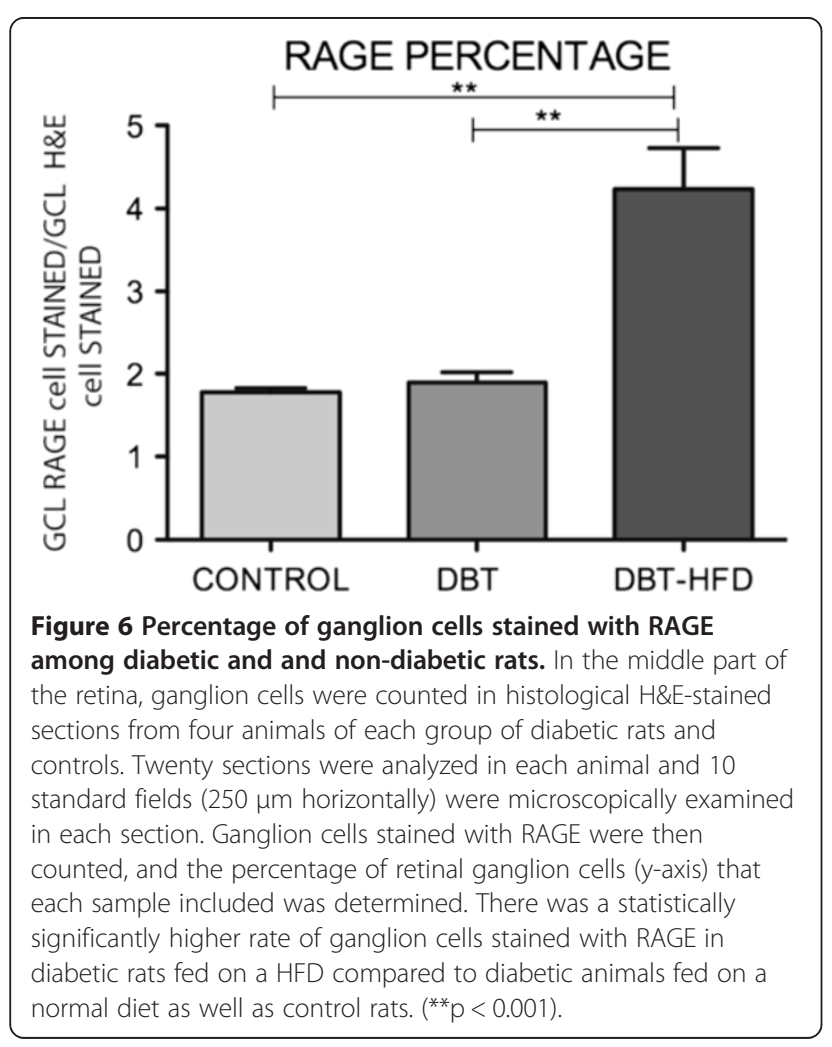

research carried out in VEGF knockout mice investigators reported a significantly reduced expression of inflammatory biomarkers, a relatively low number of acellular capillaries, and less vascular leakage compared to a group of diabetic control mice [39]. A VEGF antagonist, the pigment-epithelium-derived-factor (PEDF), reduces the effect of VEGF [40]. In patients, bevacizumab, pegaptanib, and ranibizumab (antiVEGF agents) are intravitreously injected in diabetic retinopathy and exudative macular degeneration. Aflibercept (VEGF Trap Eye) will be soon incorporated into clinical use. Nevertheless, a longing acting drug with a less frequent need for injections has not been found yet. Anyway, it is of ophthalmic interest that susceptibility of tumor cells to antiVEGF agents is dissimilar [41], probably due to levels of VEGFR2. Resistant cases have been found in association with low levels of VEGFR2. To our knowledge, this has not been investigated in the eye. Ophthalmologists are aware of cases of diabetic macular edema and proliferative diabetic retinopathy that minimally respond to antiVEGF therapy. Drug delivery systems or nanoparticles functionalized with antiVEGF molecules could be used to work this out [42].

The role of the inflammatory cytokine TNF- $\alpha$ in the pathogenesis of diabetic retinopathy is well established. In recent investigations, retinal inflammation and apoptosis of microvascular cells and neurons were significantly reduced in the absence of TNF- $\alpha$ [43]. In rheumatoid arthritis and other systemic inflammatory diseases several TNF- $\alpha$ inhibitors have been used (adalimunab [humira], etanercept [enbrel], infliximab [remicade]) [44]. Cimzia is a new TNF-blocker, which shows less toxicity and a higher affinity to human TNF [45]. Actemra is a monoclonal antibody blocker of IL- 6 that also affects TNF- $\alpha$. The two TNF- $\alpha$ receptors, TNFR1 and TNFR2, have been found to be involved in ischemia reperfusion injury and would be interesting targets for pharmacological therapies [46]. 


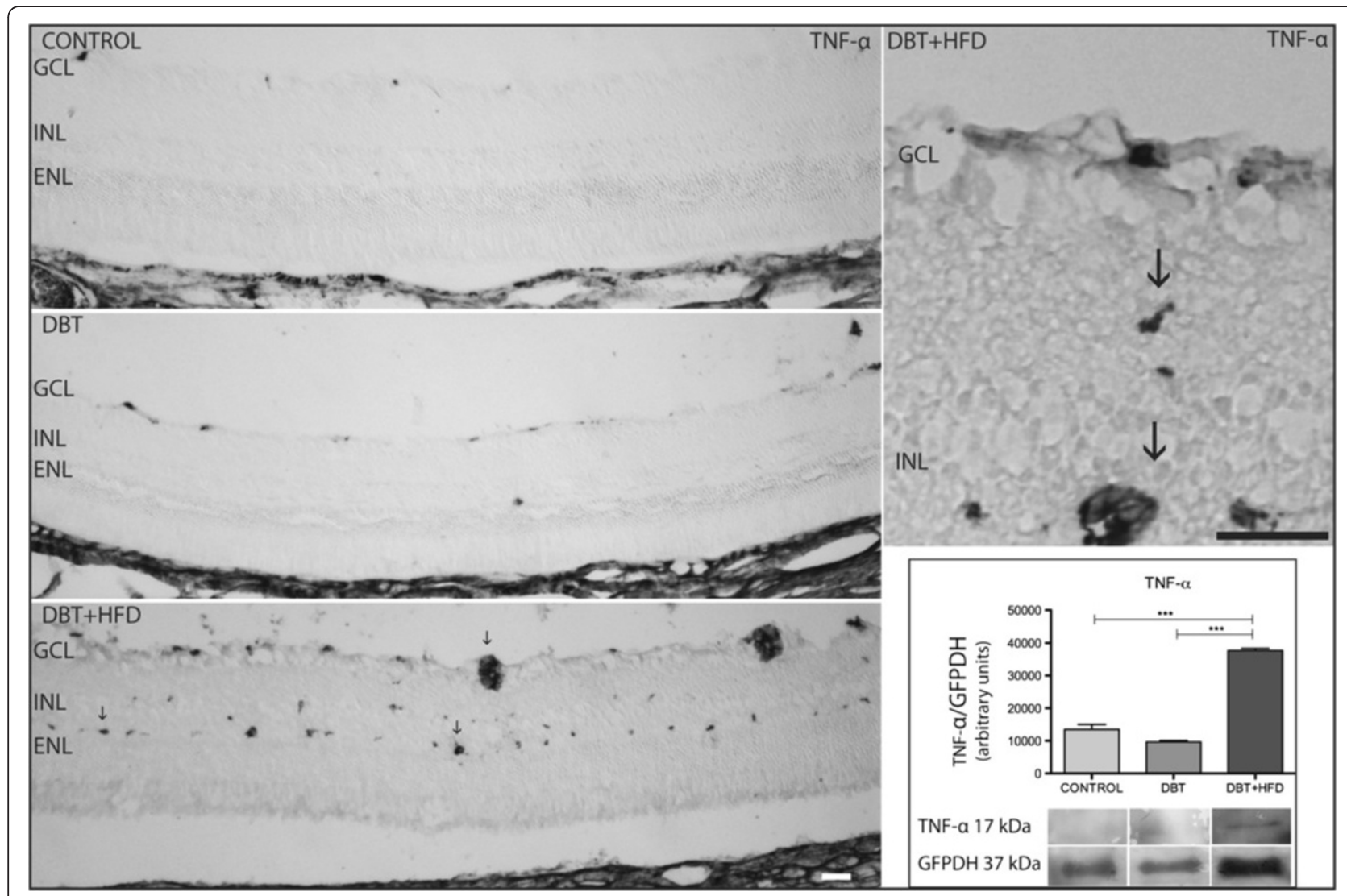

Figure 7 TNF-a retinal expression. The immunohistochemical expression of TNF-a was found to be upregulated in vessels of the inner retina of the diabetic group fed on a HFD (arrows) compared to diabetic group on a normal diet and controls. Barr $10 \mu m$. Western blot confirms the higher expression in the diabetic group on a HFD. $\left(^{* * *} p<0.0005\right)$.

Finally, a recent research study reported that TNF- $\alpha$ resistance promotes drug resistance in malignant tumors $[47,48]$ posing an interesting hypothesis for analysis in eye research.

In a study done in humans on the profile of lipids and proteins with paracrine functions encountered in the vitreous, the progression of diabetic retinopathy correlated with increased levels of 5-LO metabolites and VEGF, which is to some extend similar to the findings of our study [49]. In our opinion several inflammatory and proangiogenic factors are involved in the development of diabetic retinopathy. However, most ocular treatments have included monotherapies. This approach contrasts with what is often implemented in oncology, that is to say, combined pharmacological therapies, targeting different sites to tackle several disease mechanisms [50]. We think that combined

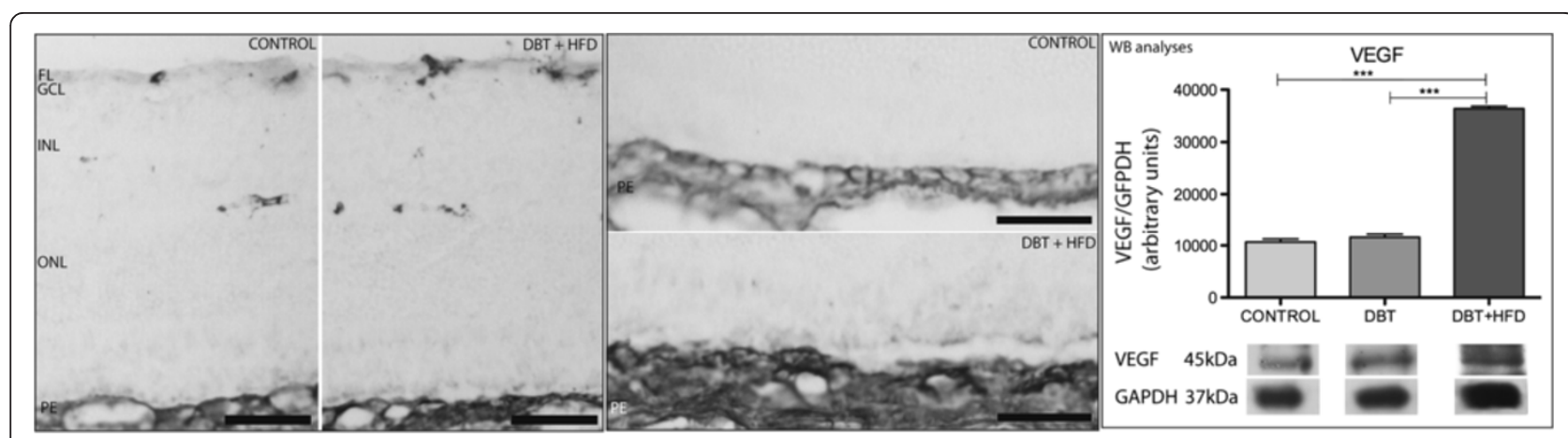

Figure 8 Immunohistochemical analysis of VEGF expression in the different retinal layers. A higher expression was found in diabetic rats on a HFD compared to controls. VEGF expression in the different layers: the fiber layer (FL), outer plexiform layer (OPL) and retinal pigment epithelium (RPE). Bar $50 \mu \mathrm{m}$. Western blot confirms the higher expression of VEGF in the HFD group. $\left({ }^{* * *} \mathrm{p}<0.0001\right)$. 


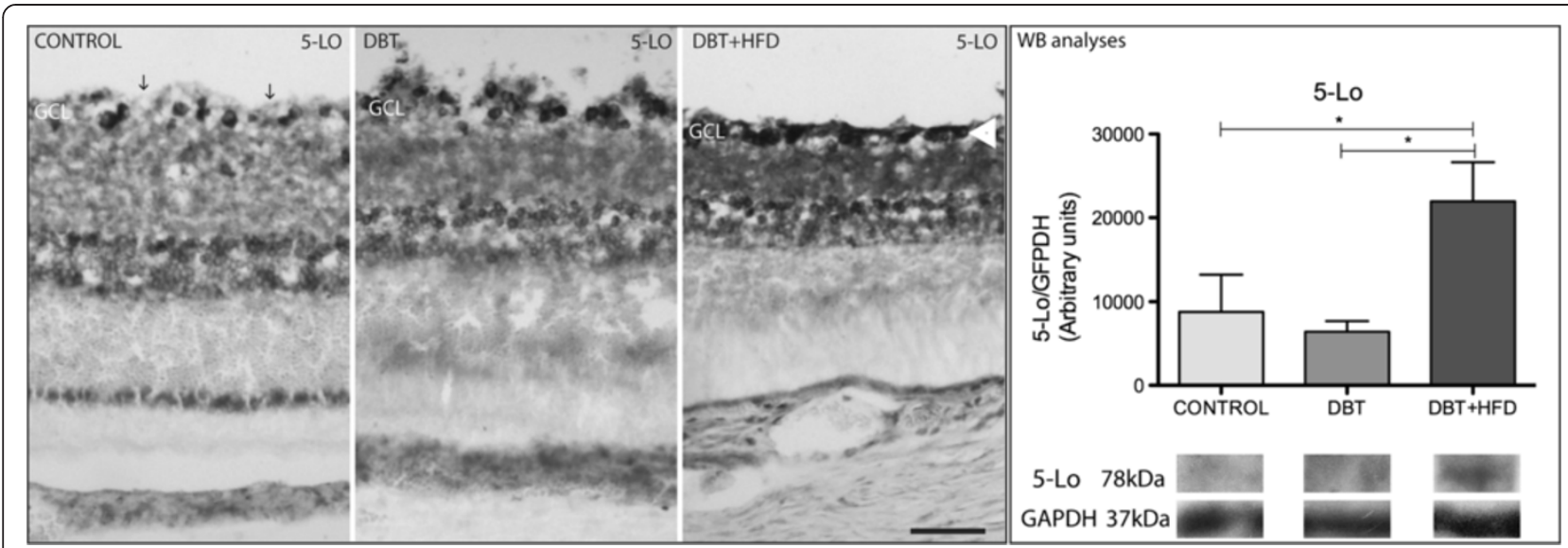

Figure 9 Immunohistochemical analyses of 5-LO. A similar immunohistochemical pattern was observed in the three groups of animals. The control group shows stained cells separated by free space (arrows) in the GCL while staining in the GCL of the HFD group is much more dense (arrow head). Bar $50 \mu \mathrm{m}$. The difference was confirmed by WB analyses. $\left({ }^{*} \mathrm{p}<0.05\right)$.

pharmacological therapies should be tested more frequently in experimental diabetic retinopathy studies.

\section{Conclusions}

It is noteworthy that an injection of $45 \mathrm{mg} / \mathrm{kg}$ of STZ and a HFD resulted in much more retinal changes than a single STZ injection of $90 \mathrm{mg} / \mathrm{kg}$ in rats. These results support the hypothesis of a synergistic effect of lipotoxicity and glucotoxicity on the retina. The model of neonatal diabetic rats fed on a HFD seems to be useful to further evaluate mechanisms involved in diabetic retinopathy progression as well as to find new therapeutic targets.

\section{Abbreviations}

HFD: High fat diet; GFAP: Glial fibrillary acidic protein; IRMA: Intra retinal microvascular alterations; STZ: Streptozotocin; VEGF: Vascular endothelial growth factor; RAGE: Receptor of advanced glycation end products; 5-Lo: 5 lipo-oxigenase; TNF-a: Tumor necrosis factor-alpha; GFPDH: Glyceraldehyde3-phosphate dehydrogenase; GCL: Ganglion cell layer; IPL: Inner plexiform layer; INL: Inner nuclear layer; OPL: Outer plexiform layer; RPE: Retinal pigment epithelia; WB: Western blot; AA: Arachidonic acid.

\section{Competing interests}

The authors declare that they have no competing interests.

\section{Authors' contributions}

JEM: AB, MT, ES, FG; GO: AB, MT; JC: MT, FG; JEG: MT, ES, FG. All authors read and approved the final manuscript.

\section{Acknowledgments}

We are grateful to Guillermo Gaston, Soledad Arregui and Norma Montalbetti for their skilful technical assistance.

\author{
Author details \\ ${ }^{1}$ Nanomedicine \& Vision Group, Facultad de Ciencias Biomédicas, \\ Universidad Austral, Pilar, Buenos Aires, Argentina. ${ }^{2}$ Department of \\ Ophthalmic Pathology, Fundación Oftalmológica Argentina "Jorge Malbran", \\ Buenos Aires, Argentina.
}

Received: 23 October 2012 Accepted: 11 April 2013

Published: 15 April 2013

\section{References}

1. Marx J: Unraveling the causes of diabetes. Science 2002, 296(5568):686-689.

2. Tataranni PA, Bogardus C: Changing habits to delay diabetes. N Engl J Med 2001, 344(18):1390-1392.

3. Sinha R, Fisch G, Teague B, Tamborlane WV, Banyas B, Allen K, et al: Prevalence of impaired glucose tolerance among children and adolescents with marked obesity. N Engl J Med 2002, 346(11):802-810.

4. Steinbrook R: Facing the diabetes epidemic-mandatory reporting of glycosylated hemoglobin values in New York City. N Engl J Med 2006, 354(6):545-548.

5. Winer N, Sowers JR: Epidemiology of diabetes. J Clin Pharmacol 2004, 44(4):397-405.

6. Li Q, Zemel E, Miller B, Perlman I: Early retinal damage in experimental diabetes: electroretinographical and morphological observations. Exp Eye Res 2002, 74(5):615-625.

7. Chew EY: A simplified diabetic retinopathy scale. Ophthalmology 2003, 110(9):1675-1676.

8. Yamada H, Yamada E, Higuchi A, Matsumura M: Retinal neovascularisation without ischaemia in the spontaneously diabetic Torii rat. Diabetologia 2005, 48(8):1663-1668.

9. Bonner-Weir S, Trent DF, Honey RN, Weir GC: Responses of neonatal rat islets to streptozotocin: limited B-cell regeneration and hyperglycemia. Diabetes 1981, 30(1):64-69.

10. Pascoe WS, Storlien LH: Inducement by fat feeding of basal hyperglycemia in rats with abnormal beta-cell function. Model for study of etiology and pathogenesis of NIDDM. Diabetes 1990, 39(2):226-233.

11. Chen WJD, Grant MB, Esselman JE, Busik JV: Dyslipidemia-Induced Adhesion Molecule Expression in hRVE Cell. Invest Ophthalmol Vis Sci 2003, 44(11):5016-5022.

12. Pascoe WS, Jenkins $A B$, Kusunoki M, Storlien $L H$ : Insulin action and determinants of glycaemia in a rat model of type 2 (non-insulindependent) diabetes mellitus. Diabetologia 1992, 35(3):208-215.

13. Weir GC, Clore ET, Zmachinski CJ, Bonner-Weir S: Islet secretion in a new experimental model for non-insulin-dependent diabetes. Diabetes 1981, 30(7):590-595.

14. Bradford MM: A rapid and sensitive method for the quantitation of microgram quantities of protein utilizing the principle of protein-dye binding. Anal Biochem 1976, 72:248-254.

15. Kuwabara T, Cogan DG: Studies of retinal vascular patterns. I. Normal architecture. Arch Ophthalmol 1960, 64:904-911.

16. Fantus IG, Chayoth R, O'Dea L, Marliss EB, Yale JF, Grose M: Insulin binding and glucose transport in adipocytes in neonatal streptozocin-injected rat model of diabetes mellitus. Diabetes 1987, 36(5):654-660.

17. Srinivasan K, Viswanad B, Asrat L, Kaul CL, Ramarao P: Combination of highfat diet-fed and low-dose streptozotocin-treated rat: a model for type 2 diabetes and pharmacological screening. Pharmacol Res 2005, 52(4):313-320. 
18. Gravina CF, Bertolami M, Rodrigues GH: Dyslipidemia: evidence of efficacy of the pharmacological and non-pharmacological treatment in the elderly. J Geriatr Cardiol 2012, 9(2):83-90.

19. De Lorgeril M, Renaud S: Mamelle N, al e. Mediterranean alpha-linoleic acid-rich diet in secondary prevention of coronary heart disease. Lancet 1994, 343:1454-1459.

20. De Lorgeril M, Salen P, Martin JM, Monjaud I, Delaye J, Mamelle N: Mediterranean diet, traditional risk factors, and the rate of cardiovascular complications after myocardial infarction: final report of the Lion Diet Heart Study. Circulation 1999, 99:779-785.

21. Siscovick DS, Raghunathan T, King I, et al: Dietary intake of long-chain n-3 polynsaturated fatty acids and the of primary cardiac arrest. Am J Clin Nutr 2000, 71:208-212.

22. Bazan NG: Survival signaling in retinal pigment epithelial cells in response to oxidative stress: significance in retinal degenerations. Adv Exp Med Biol 2006, 572:531-540

23. Bazan N: Cell survival matters: docosahexaenoic acid signaling, neuroprotection and photoreceptors. Trends Neurosci 2006, 29(5):263-271.

24. Lukiw WJ, Cui JG, Marcheselli VL, Bodker M, Botkjaer A, Gotlinger K, et al: A role for docosahexaenoic acid-derived neuroprotectin D1 in neural cell survival and Alzheimer disease. J Clin Invest 2005, 115(10):2774-2783.

25. Samuelsson B, Dahlen SE, Lindgren JA, Rouzer CA, Serhan CN: Leukotrienes and lipoxins: structures, biosynthesis, and biological effects. Science 1987, 237(4819):1171-1176.

26. Talahalli R, Zarini S, Sheibani N, Murphy RC, Gubitosi-Klug RA: Increased synthesis of leukotrienes in the mouse model of diabetic retinopathy. Invest Ophthalmol Vis Sci 2010, 51(3):1699-1708.

27. Sanchez-Galan E, Gomez-Hernandez A, Vidal C, Martin-Ventura JL, BlancoColio LM, Munoz-Garcia B, et al: Leukotriene B4 enhances the activity of nuclear factor-kappaB pathway through BLT1 and BLT2 receptors in atherosclerosis. Cardiovasc Res 2009, 81(1):216-225.

28. Zong H, Ward M, Stitt AW: AGEs, RAGE, and diabetic retinopathy. Curr Diab Rep 2011, 11(4):244-252.

29. Lisovyy OO, Dosenko VE, Nagibin VS, Tumanovska LV, Korol MO, Surova OV, et al: Cardioprotective effect of 5-lipoxygenase gene (ALOX5) silencing in ischemia-reperfusion. Acta Biochim Pol 2009, 56(4):687-694.

30. Hardy P, Beauchamp M, Sennlaub F, Gobeil F Jr, Tremblay L, Mwaikambo B, et al: New insights into the retinal circulation: inflammatory lipid mediators in ischemic retinopathy. Prostaglandins Leukot Essent Fatty Acids 2005, 72(5):301-325.

31. Gubitosi-Klug RA, Talahalli R, Du Y, Nadler JL, Kern TS: 5-Lipoxygenase, but not 12/15-lipoxygenase, contributes to degeneration of retinal capillaries in a mouse model of diabetic retinopathy. Diabetes 2008, 57(5):1387-1393.

32. Stahl A, Sapieha P, Connor KM, Sangiovanni JP, Chen J, Aderman CM, et al: Short communication: PPAR gamma mediates a direct antiangiogenic effect of omega 3-PUFAs in proliferative retinopathy. Circ Res 2010, 107(4):495-500.

33. Sapieha P, Stahl A, Chen J, Seaward MR, Willett KL, Krah NM, et al: 5Lipoxygenase metabolite 4-HDHA is a mediator of the antiangiogenic effect of omega-3 polyunsaturated fatty acids. Sci Trans/ Med 2011 3(69):69ra12.

34. Rossi A, Pergola C, Koeberle A, Hoffmann M, Dehm F, Bramanti P, et al: The 5-lipoxygenase inhibitor, zileuton, suppresses prostaglandin biosynthesis by inhibition of arachidonic acid release in macrophages. $\mathrm{Br} J$ Pharmacol 2010, 161(3):555-570.

35. Kaji Y, Usui T, Ishida S, Yamashiro K, Moore TC, Moore J, et al: Inhibition of diabetic leukostasis and blood-retinal barrier breakdown with a soluble form of a receptor for advanced glycation end products. Invest Ophthalmol Vis Sci 2007, 48(2):858-865.

36. Shoji T, Koyama H, Morioka T, Tanaka S, Kizu A, Motoyama K, et al: Receptor for advanced glycation end products is involved in impaired angiogenic response in diabetes. Diabetes 2006, 55(8):2245-2255.

37. Yamagishi S, Nakamura K, Matsui T: Advanced glycation end products (AGEs) and their receptor (RAGE) system in diabetic retinopathy. Curr Drug Discov Technol 2006, 3(1):83-88.

38. Mizutani M, Gerhardinger C, Lorenzi M: Muller cell changes in human diabetic retinopathy. Diabetes 1998, 47(3):445-449.

39. Wang J, Xu X, Elliott MH, Zhu M, Le YZ: Muller cell-derived VEGF is essential for diabetes-induced retinal inflammation and vascular leakage. Diabetes 2010, 59(9):2297-2305.
40. Zhang SX, Wang JJ, Gao G, Shao C, Mott R, Ma JX: Pigment epitheliumderived factor (PEDF) is an endogenous antiinflammatory factor. FASEB J 2006, 20(2):323-325.

41. Sitohy B, Nagy JA, Jaminet SC, Dvorak HF: Tumor-surrogate blood vessel subtypes exhibit differential susceptibility to anti-VEGF therapy. Cancer Res 2011, 71(22):7021-7028.

42. Stewart MW, Rosenfeld PJ, Penha FM, Wang F, Yehoshua Z, Bueno-Lopez E, et al: Pharmacokinetic Rationale for Dosing Every 2 Weeks Versus 4 Weeks with Intravitreal Ranibizumab, Bevacizumab, and Aflibercept (Vascular Endothelial Growth Factor Trap-Eye). Retina 2012, 32(3):434-457.

43. Huang H, Gandhi JK, Zhong X, Wei Y, Gong J, Duh EJ, et al: TNFalpha is required for late $B R B$ breakdown in diabetic retinopathy, and its inhibition prevents leukostasis and protects vessels and neurons from apoptosis. Invest Ophthalmol Vis Sci 2011, 52(3):1336-1344.

44. Kim IH, West CE, Kwatra SG, Feldman SR, O'Neill JL: Comparative efficacy of biologics in psoriasis: a review. Am J Clin Dermatol 2012, 13(6):365-374.

45. Weinblatt ME, Fleischmann R, Huizinga TW, Emery P, Pope J, Massarotti EM, et al: Efficacy and safety of certolizumab pegol in a broad population of patients with active rheumatoid arthritis: results from the REALISTIC phase IIlb study. Rheumatology (Oxford) 2012, 51(12):2204-2214.

46. Gesslein B, Hakansson G, Gustafsson L, Ekstrom P, Malmsjo M: Tumor necrosis factor and its receptors in the neuroretina and retinal vasculature after ischemia-reperfusion injury in the pig retina. Mol Vis 2010, 16:2317-2327.

47. Antoon JW, White MD, Burow ME, Beckman BS: Dual inhibition of sphingosine kinase isoforms ablates TNF-induced drug resistance. Oncol Rep 2012, 27(6):1779-1786.

48. Radeff-Huang j, Seasholtz TM, Chang J, Smith J, Walsh C, Brown J: Tumor necrosis factor-alpha-stimulated cell proliferation is mediated through sphingosine kinase-dependent Akt activation and cyclin D expression. J Biol Chem 2007, 282:863-870.

49. Schwartzman ML, Iserovich P, Gotlinger K, Bellner L, Dunn MW, Sartore M, et al: Profile of lipid and protein autacoids in diabetic vitreous correlates with the progression of diabetic retinopathy. Diabetes 2010, 59(7):1780-1788.

50. Xu T, Chen J, Lu Y, Wolff JE: Effects of bevacizumab plus irinotecan on response and survival in patients with recurrent malignant glioma: a systematic review and survival-gain analysis. BMC Cancer 2010, 10:252.

doi:10.1186/1471-2415-13-14

Cite this article as: Mancini et al.: Retinal upregulation of inflammatory and proangiogenic markers in a model of neonatal diabetic rats fed on a high-fat-diet. BMC Ophthalmology 2013 13:14

\section{Submit your next manuscript to BioMed Central and take full advantage of:}

- Convenient online submission

- Thorough peer review

- No space constraints or color figure charges

- Immediate publication on acceptance

- Inclusion in PubMed, CAS, Scopus and Google Scholar

- Research which is freely available for redistribution 